Submission ID: 43808

\title{
A Complex of Geological and Geophysical Methods for Determining the Spatial Position of Zones with Different Filtration Properties in Limestones of the Khalah Formation
}

A.G. Kobzev* (Saint Petersburg research and survey Institute "Energoiziskanya" (JSC "Spb EIZ"), S.A. Pereverzeva (SPbSU), T.A. Berdichevskaya (SPbSU), N.A. Vaskova (JSC "Spb EIZ"), A.E. Ovinnikov (JSC "Spb EIZ")

\section{SUMMARY}

The studied porous-cavernous carbonate rocks of the Khalah formation of the North-Western desert of Egypt are represented mainly by cavernous limestones, in the lower part of fine-grained chalky and marly limestones. Throughout the work area, limestones are blocked by younger sandstone calcareous with stratigraphic disagreement. In the roof of limestones, the weathering crust is represented by sections of scabrous rocks with loamy aggregate of 1 to $3 \mathrm{~m}$ in thickness. In the present study, two problems were solved:

1. Study of the pore space of limestones of the Khalah formation

2. The positions in the space of the zones of these rocks with different physical properties, characterizing permeability.

The solution of these problems is connected with the subsequent construction of industrial facilities in the territory under consideration. To solve these problems, a set of geological and geophysical methods was applied. 
Комплекс геолого-геофизических методов при определении пространственного положения зон с различными фильтрационными свойствами в известняках формации Хала.

А.Г.Кобзев*(АО "СПб НИИИ "Энергоизыскания"), С.А.Переверзева (СПбГУ), Т.А. Бердичевская (СПбГУ), Н.А.Васькова (АО "СПб НИИИ "Энергоизыскания"), А.Е. Овинников (АО "СПб НИИИ "Энергоизыскания").

\section{Введение}

Изучаемые порово-каверновые карбонатные породы формации Хала Северо-Западной пустыни Египта представлены преимущественно известняками-ракушечниками кавернозными, в нижней части мелкозернистыми меловыми и мергелистыми известняками. На всем участке работ известняки перекрыты более молодыми песчаниками известковистыми со стратиграфическим несогласием. В кровле известняков участками наблюдается кора выветривания, представленная дресвяно-щебнистыми породами с супесчаным заполнителем мощностью от 1 до 3 м.

В настоящем исследовании решались 2 задачи:

1. Изучение порового пространства известняков формации Хала

2. Положения в пространстве зон этих пород с различными физическими свойствами, характеризующими проницаемость.

Решение этих задач связано с последующим строительством промышленных объектов на рассматриваемой территории [2]. Для решения поставленных задач применялся комплекс геолого-геофизических методов.

\section{Методы исследований}

Методы исследований включали оценку значений общей пористости известняков в отдельных точках наблюдения, геостатистический анализ пространственного распределения значений общей пористости и пространственное совмещении полученных данных с другими геологическими и геофизическими данными в среде ArcGis с целью выделения зон с повышенной проницаемостью.

Полуколичественная оценка пористости известняков включала следующие методы исследования:

1. Рентгенографическая микротомография, позволяющий строить трехмерные модели горных пород с большим разрешением. По результатам рентгенографических исследований можно судить о количественной характеристике пористости, а также о характере ее распределения.

2. Изучение прозрачных петрографических шлифов с визуальной оценкой общей пористости.

3. Расчет общей пористости через плотность, определенную лабораторным методом (Лабораторный метод).

Рентгенографическая томография проводилась в лаборатории СПбГУ на микротомографе SkyScan 1172. Были получены послойные срезы, характеризующие микропоровое пространство образцов известняка со скважины 1 на глубинах -27 и -36 м. Произведена количественная оценка общей пористости.

Изучение петрографических шлифов проводилось в петрографической лаборатории ВСЕГЕИ. Были изучены шлифы из образцов известняка, отобранных на различных глубинах в скважине 1 и ещё с шести скважин. Наряду с петрографическим описанием состава породы производилась визуальная оценка пористости.

Количественное определение общей пористости образцов проводилось в 28 скважинах на различных глубинах. Стоит отметить, что размеры исследуемых образцов, при использовании 


\section{EAGE}

различных методов - различаются: размеры шлифа - первые сантиметры; размеры образца (столбика) для микротомографа - диаметр $\sim 1$ см и высота - первые сантиметры; размеры образца для лабораторного определения - ширина, длина и высота составляют до $10 \mathrm{cm.}$

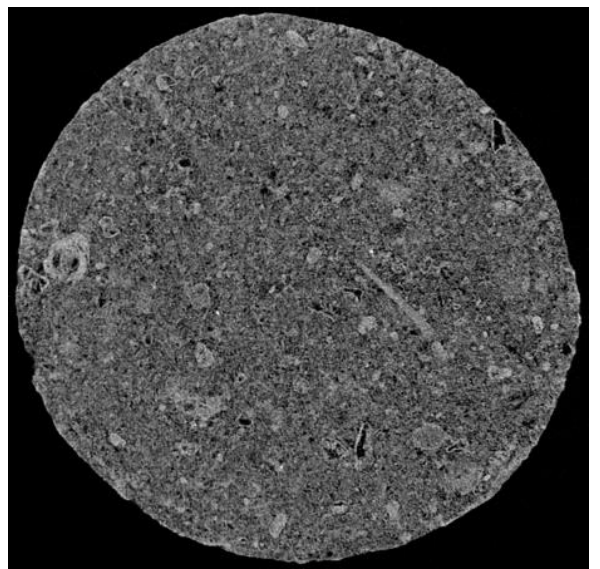

a)

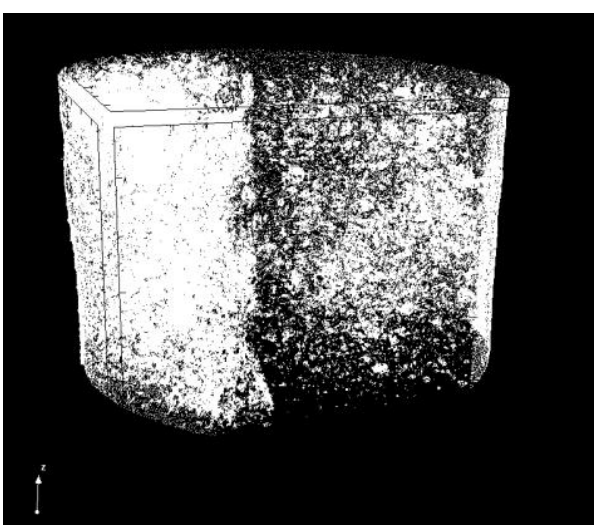

B)

Рисунок 1. Результаты рентгеновской томографии, петрографического описания шлифа и образиа керна известняка а) - поперечный срез исследуемого образиа известняка по данным микротомографии. б) - Фотография прозрачного илифа известняка. Николи скрещень. в) - 3D визуализация распределения пор в образие известняка по данным микротомографии. Бельлм цъветом показана матрица известняка, пустоть -прозрачные. г) - фотография образца керна пористого кавернозного известняка

Результаты сравнения данных величины пористости, полученных по рентгенографическим исследованиям, шлифам и лабораторным методом представлены в таблице 1.

\begin{tabular}{|l|l|l|l|}
\hline \multirow{2}{*}{$\begin{array}{l}\text { Глубина } \\
\text { отбора, м }\end{array}$} & \multicolumn{3}{|c|}{ Величина общей пористости, \% } \\
\cline { 2 - 4 } & $\begin{array}{l}\text { Рентгенографическое } \\
\text { исследование }\end{array}$ & Шлифовой анализ & Лабораторный метод \\
\hline 27 & 2,06 & 5 & 48 \\
\hline 36 & 0,43 & $10-15$ & 53 \\
\hline 42 & 3,47 & $5-10$ & 41 \\
\hline
\end{tabular}

Из таблицы 1 видно, что величины общей пористости, полученные по результатам микротомографии и шлифовому анализу в целом сопоставимы друг с другом. Однако, на порядок отличаются от значения общей пористости, полученному лабораторным методом. Это 


\section{EAGE}

может объясняться масштабным эффектом. Кроме того, имея ввиду, что известняк является трещиновато-пористой породой [1], можно предположить, что в масштабах образцов для рентгенографических исследований и петрографического анализа определяется матричная пористость [3], а при определении лабораторным методом, величина общей пористости характеризует все трещинно-поровое пространство.

Трещиноватость и кавернозность известняков отмечалась и оценивалась также при визуальном описании керна буровых скважин. Степень сохранности керна характеризуется параметром RQD, который оценивается визуально при документации как процентное отношение суммарной длины образцов керна длиной более 10 см к общей длине пробуренного интервала [2]. Можно предположить, что RQD в значительной степени зависит от степени трещиноватости породы. Исходя из этого предположения, был проведен геостатистический анализ распределения значений RQD в пространстве толщи известняков. Распределение значений RQD по разрезу, проходящему через скважину 1, показано на рисунке 2

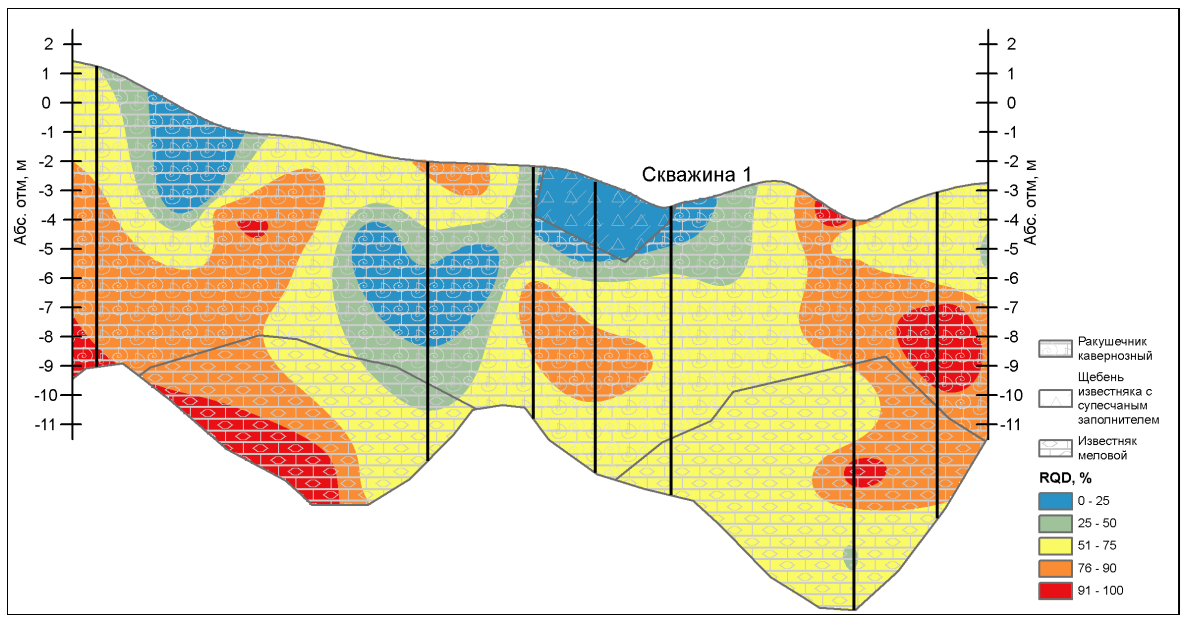

Рисунок 2. Распределение RQD по разрезу

Средствами ArcGis были отфильтрованы 3D точки с определениями скоростей продольных волн именно в толще известняков и проведен геостатистический анализ полученных данных. Распределение продольных волн по разрезу показано на рисунке 3

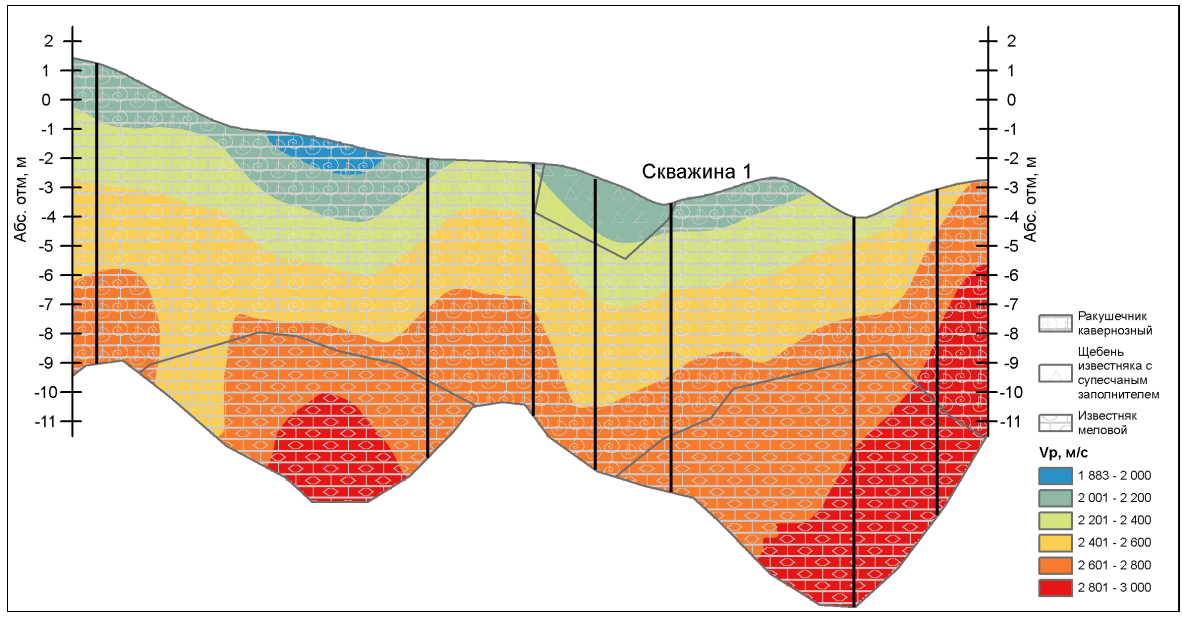

Рисунок 3. Распределение Vр по разрезу 
Для пространственного выделения зон с повышенной проницаемостью по геологическим и геофизическим данным была построена цифровая 3D модель геологического строения участка работ и $3 \mathrm{D}$ модель распределения значений скоростей продольных волн $(\mathrm{Vp})$. В цифровой $3 \mathrm{D}$ модели геологического строения известняки были отделены от перекрывающих отложений (рисунок 5).

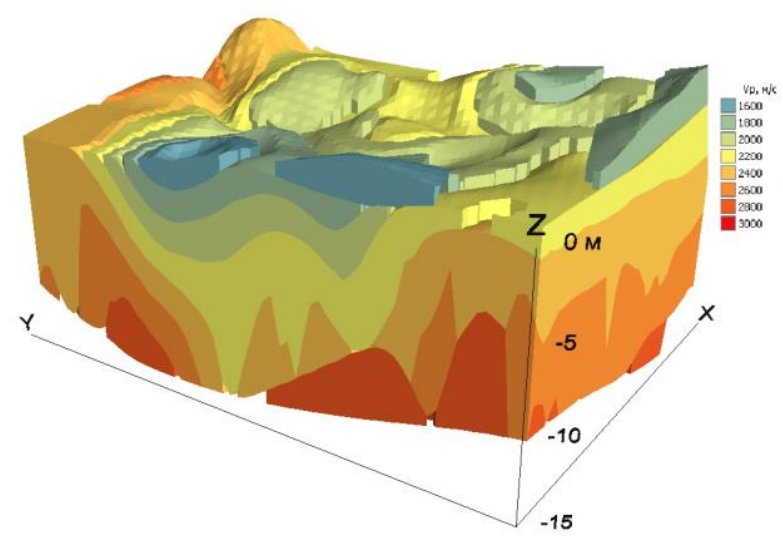

a)

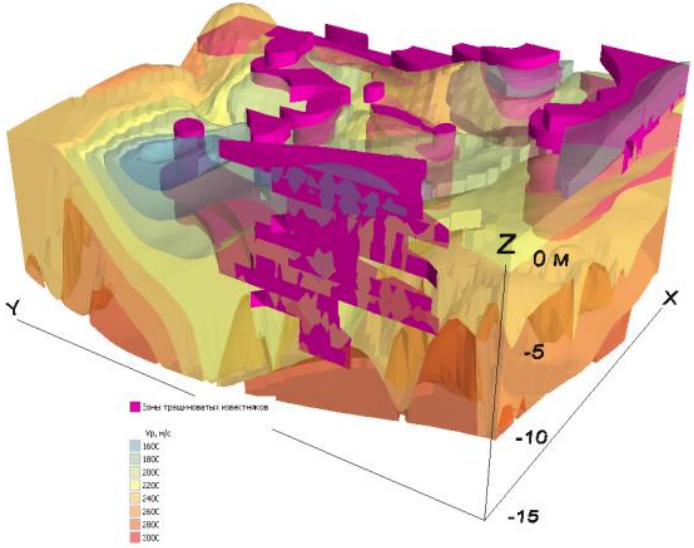

б)

Рисунок 5. а) - 3D модель распределения значений скоростей продольных волн (Vp). б) Пространственное совмещение $3 D$ модели распределения значений скоростей продольных волн $(V p)$ с 3D моделью пространственного распространения сильно трещиноватых пород.

На основании проведенных исследований были сделаны следующие выводы:

1. По результатам исследований методом рентгенографической томографии известняки характеризуется низкой пористостью 1-2\%.

2. Результаты визуального описания керна скважин и расчеты общей пористости через плотность позволяют предположить, что значительную роль в общем объеме пустотного пространства известняков играют каверны различного размера. Кавернозность известняков неравномерная по разрезу и по площади.

3. Результаты визуального описания керна скважин и расчеты общей пористости через плотность позволяют предположить, что значительную роль в общем объеме пустотного пространства известняков играют микро и макротрещины, как одиночные, так и образующие зоны трещиноватости.

4. Геофизические данные и результаты обработки данных визуального описания керна скважин позволяют предположить, что зоны трещиноватости, вплоть до образования скоплений щебня, большей частью приурочены к кровле известняков.

5. Пониженные значения скоростей продольных сейсмических волн могут указывать на положение зон трещиноватости .

\section{Библиография}

1. Багринцева К.И. Условия формирования и свойства карбонатных коллекторов нефти и газа. М.: РГГУ,1999, с. 12.

2. ГОСТ 25100-2011 Грунты. Классификация

3. Michael C. Sukop, Kevin J. Cunningham. Geostatistical Borehole Image-Based Mapping of KarstCarbonate Aquifer Pores. //Vol. 54, No. 2-Groundwater-March-April 2016 (pages 202-213), doi:

\section{References} $10.1111 /$ gwat. 12354

1. Bagrintseva K.I. Formation conditions and properties of carbonate reservoirs of oil and gas. - Moscow: RSUH, 1999, 12 p.

2. GOST 25100-2011 Soils. Classification 


\section{EAGE}

EUROPEAN

GEOSCIENTISTS \&

3. Michael C. Sukop, Kevin J. Cunningham. Geostatistical Borehole Image-Based Mapping of KarstCarbonate Aquifer Pores. //Vol. 54, No. 2-Groundwater-March-April 2016 (pages 202-213), doi: $10.1111 /$ gwat.12354 